\title{
Blue Market: A Reproduction of the Industrial Environment in the Class- room (RAIS) experience
}

\section{Dr. Raquel Landa, Tecnologico de Monterrey (ITESM)}

Part-time teacher at Tec de Monterrey since 1999, with a Ph.D. in Education, a Master in Information Technology Management and a Major in Electronic Systems. Currently involved in Innovation projects related to engineering and programming courses.

\section{Dr. Lorena B. Martinez Elizalde, Tecnologico de Monterrey Ing. Cristina Verónica Gonzalez Cordova, ITESM}

BS in Computer Science (2001), Master Degree in Computer Science (2003). 15 years of experience in software development, mainly web applications. Diploma in "Project Management Qualified" (PMI, 2006) and "Developing Microsoft ASP.NET Web Applications Using Visual Studio .NET" certification (2004). Cristina has participated in the entire software development process for government and industry in several áreas, like: Ministry of Health (México), Procter \& Gamble, Hewlett-Packard, Nokia, TMM, Aeromexico Airlines, VITRO, etc.

Active participation in the process of definition and certification for the company Dextra Technologies (CMM-I level 3). Cristina has also participated as speaker in congresses and symposiums organized by universities in México.

She has seven years of experience teaching in the Department of Computer Science and, since January 2019, she has been the thematic leader of continuous education and consulting of the School of Engineering and Sciences, in the area of information technologies.

Cristina lives in Monterrey, she is married and has a handsome boy and a beautiful girl. She loves play basketball, read a good book and is a caffeine fan. 


\section{Blue Market: A Reproduction of the Industrial Environment in the Classroom (RAIS) experience}

\author{
María Raquel Landa Cavazos \\ Computer Science Department \\ Tecnologico de Monterrey, \\ Campus Monterrey. \\ Monterrey, México \\ rlanda@tec.mx
}

\author{
Lorena E. Martínez Elizalde \\ Computer Science Department \\ Tecnologico de Monterrey, \\ Campus Monterrey. \\ Monterrey, México \\ lorenamtze@tec.mx
}

\author{
Cristina V. González Córdova \\ Computer Science Department \\ Tecnologico de Monterrey, \\ Campus Monterrey. \\ Monterrey, México \\ cristina.gonzalez.cordova@tec.mx
}

\section{Keywords}

RAIS, Multidisciplinarity, Experiential Learning, Active Learning.

\section{Introduction}

One of the main concerns for teachers in the 21st century is to enable challenging and significant learning environments in which students are able to develop the skills required by companies. However, it is necessary to identify the main components of meaningful learning and contextualize this learning in such a way that the students find value in these experiences. An additional factor that is essential to consider is learning can never take place in isolation and should not be considered as a series of theoretical contents that student must acquire or memorize. New models and learning strategies become relevant as they recognize that no learning can be significant if it can not be applied in a real environment. It is precisely in this pragmatic context that the different areas of knowledge interact and benefit from each other, allowing to form interdisciplinary learning teams. The following sections detail a learning experience designed and implemented based on the concepts described above.

\section{Theoretical framework}

According to [4], the vertical integration of contents refers to the relationship that occurs between subjects that precede or follow a certain course, establishing a relationship of interdependence between them. The integrated curricula approach has been adopted by many universities as a result of students' growing dissatisfaction about how basic subjects were taught as individual disciplines knowing that traditional teaching procedures do not respond to the demands of interdisciplinarity. Therefore, interdisciplinarity must be understood not as an end, but as a continuous and permanent process, in which different theories, methodologies and techniques of the scientific, technological and humanistic disciplines have to be integrated, in order to enrich the different perspectives showing the relation they have in real contexts. Since these interactions are complex, it is necessary to look for elaborated approaches that enable students to understand them [3].

From the foregoing, the question of how to achieve the proposed integration emerges. One option is the RAIS (Reproduction of the Industrial Environment in the Classroom) strategy based 
on four essential elements: active learning through construction and discovery, cooperative and collaborative learning, learning by the development of a product and the reproduction of the business environment in the classroom. In it, simulation is identified as an educational strategy that enables learning by offering students a practical scenario similar to reality, encouraging self-confidence and promoting learning through decision-making. As a result of the development of the product, students are able to build their own knowledge [1].

The RAIS approach also proposes collaborative learning, based on the principle that the collaboration among pairs significantly increases motivation, stimulates creativity, encourages and facilitates communication, develops a sense of responsibility and improves the degree of personal satisfaction [2]. Also, it raises the need to relate, contextualize and integrate the contents of the different disciplines through a set of interdisciplinary modules that have a close connection with each other. This proposal facilitates the interconnection of knowledge through an integrating element: the product to be developed.

The experience detailed in this document is based on the concepts of content integration using the RAIS approach, the activity designed involves students from three different subjects: 1) Video Game Design (VG), 2) Computational Graphics (CG) and 3) Digital Audio Systems for Web and Mobile Devices (DASWMD).

\section{Blue Market Project Description}

The "Blue Market", as this project was named, consisted of implementing, using the RAIS strategy, a client-provider model among the different subjects involved. Figure 1 shows the relationship between the different subjects as well as their roles. The concept is based on establishing a "market" of resources generated by the students of the CG and DASWMD subjects (providers) that the students of the VG subject (clients) can use in the development of their integrating project.

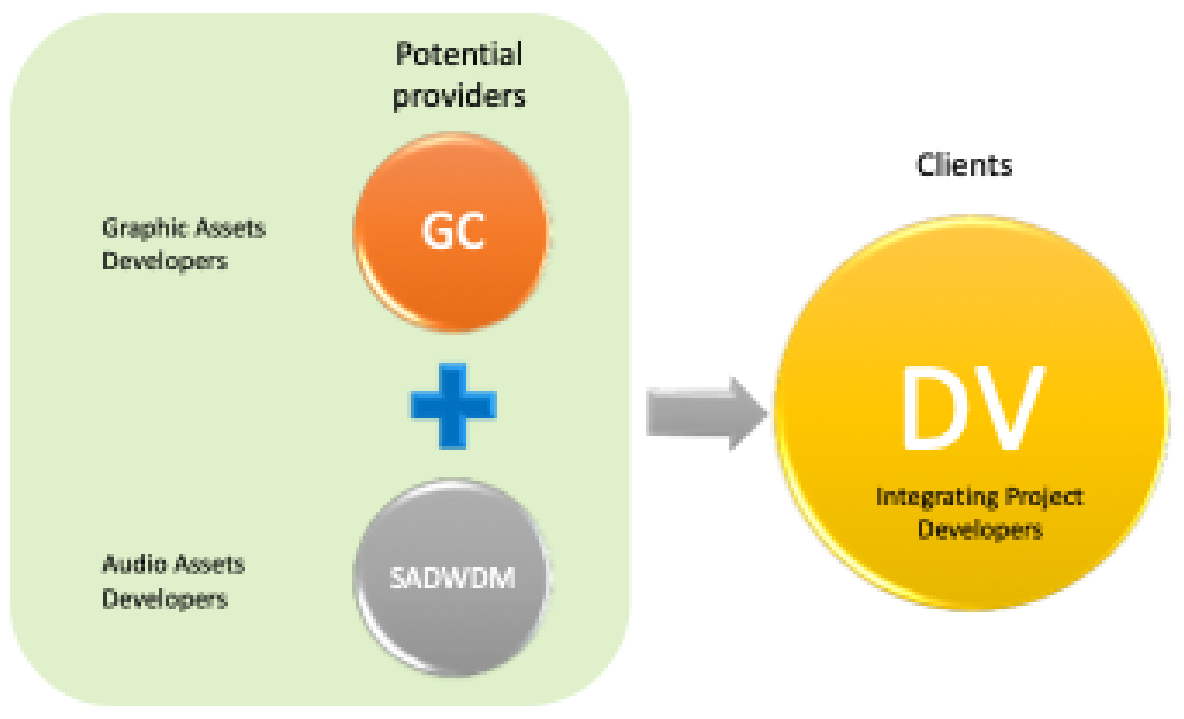

Figure 1. Roles and functions of students. 


\section{Process of implementation}

The implementation of the "Blue Market" was carried out during two consecutive semesters (Aug-Dec 2017 and Jan-May 2018) in which a total of 124 students participated. During the first semester, only two subjects were integrated (VG and DASWMD), while in the second semester a total of three subjects were integrated. Table 1 presents the details of the groups that participated. In general, the process that was followed in both implementations can be observed in Figure 2.

Table 1: Participating groups in the "Blue Market"

\begin{tabular}{|c|c|c|}
\hline \multirow{2}{*}{ Subject } & \multicolumn{2}{|c|}{ Number of Students } \\
\cline { 2 - 3 } & AD2017 & EM2018 \\
\hline VG & 30 & 28 \\
\hline DASWMD & 24 & 10 \\
\hline CG & - & 32 \\
\hline
\end{tabular}

It is important to highlight the next particularities of the process that was followed in the implementations of the "Blue Market":

- The VG teams (clients) presented their video game proposal to the potential developer teams (providers) by means of a Pitch, a short presentation in which the attributes of their project are highlighted. This presentation was decisive for the students who had the role of suppliers to decide who to work with.

- The DASWMD teams (providers) attended the first collaborative session with their portfolio of music and sound effects previously generated either during the first part of the semester and/or in other previous subjects. They even can include personal projects developed for other purposes.

- The selection of multidisciplinary work teams was carried out entirely by the students. On one hand, the providers (CG or DASWMD)approached the projects which they were interested in collaborating with after listening to the pitch. On the other hand, the clients (VG) started a dialogue, inquired and negotiated with their potential provider to select one from each subject.

- Not all VG teams managed to negotiate collaboration with the CG and/or DASWMD teams. In this case, the VG teams had the option of using resources from other sources.

- When a CG or DASWMD team (providers) had doubts or proposals for adjustments, they reviewed it directly with their client (VG team). If there was any general doubt or disagreement, they would contact the teacher in charge of the subject. 


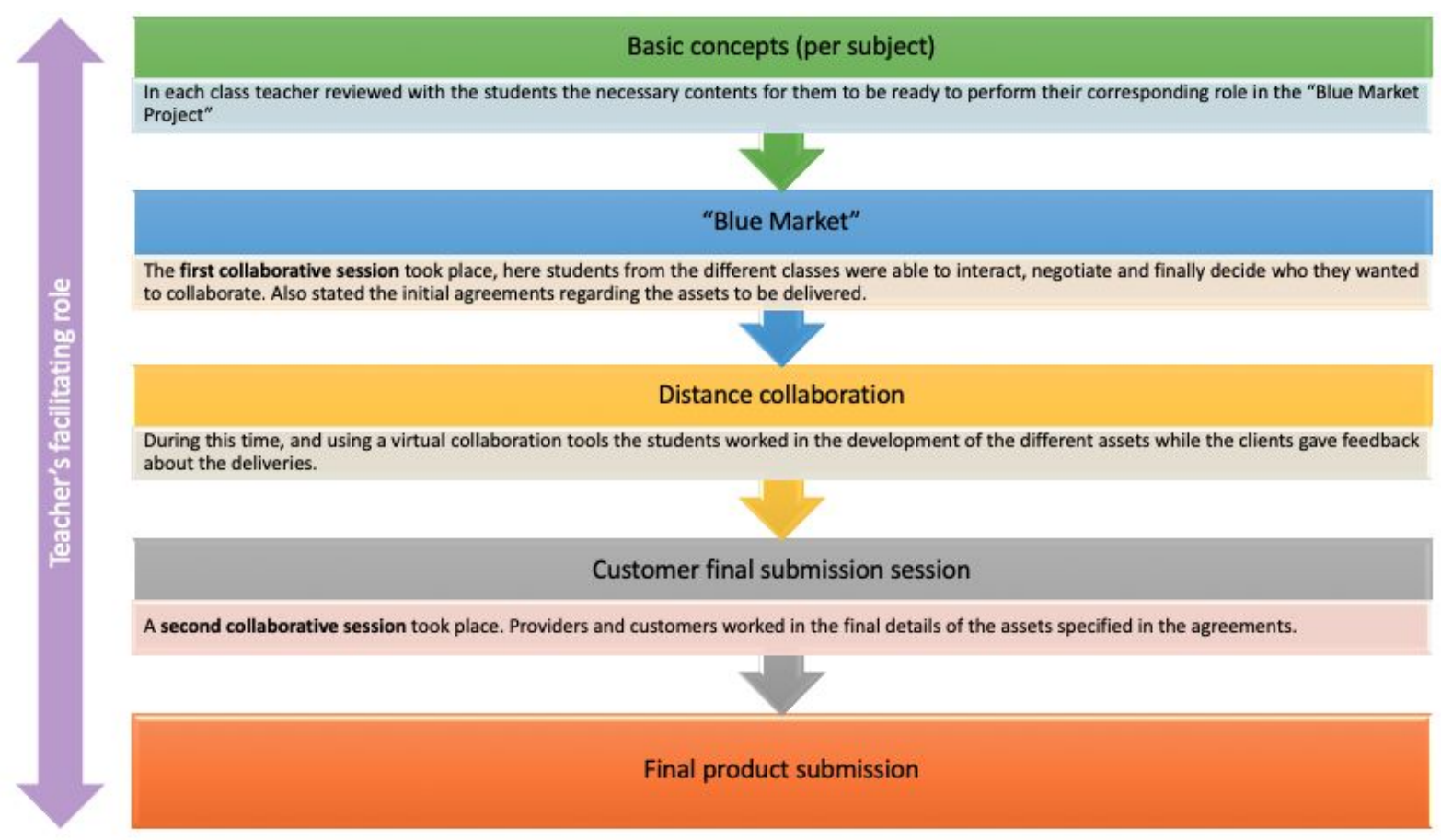

Figure 2. General implementation process

Finally, in order to gather relevant information to identify the students' perception of this activity, entrance and exit surveys were applied. The results will be discussed in the corresponding section.

\section{Evaluation of results}

In the initial surveys applied to students, they were asked to evaluate their perception of communication skills, collaborative work and use of technologies besides questioning their expectations regarding the activity. Figure 3 shows the results for this survey in terms of perception of students regarding the added value that this activity represents in its education process. It is possible to identify that the preponderant values correspond to the answer "yes", which can be interpreted as they felt this was an opportunity to collaborate, develop professional skills and apply knowledge from other classes. 


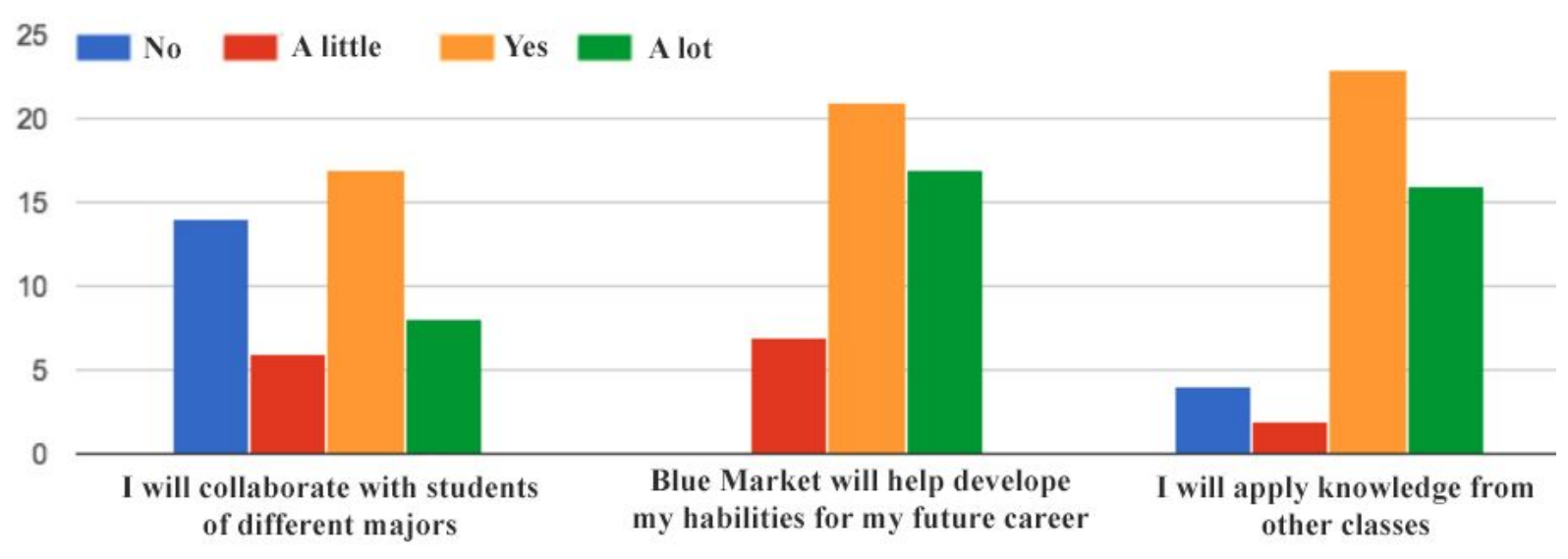

Figure 3. Perception of the students regarding the added value of the activity at the beginning of the implementation

They were asked openly what they expected from this activity. Answers obtained included comments such as: " ... it was really cool to collaborate with the different classes. I liked the idea of combining the areas", "I learned so much from the class that I'm studying, and form the knowledge that my colleagues from other classes share with me"," [Blue Market] helped me to better understand how to collaborate in large work teams and learn more about other subjects. Also, it strengthen my video game development skills with this project ". All of these comments highlighted the value of collaboration.

Specifically comparing the entry and exit surveys in terms of the impact of the activity, it is possible to observe that the participants have a very good opinion of their performance on each of the evaluated competences at the beginning and by the end of the project. We can clearly see that their perception changed in a positive way. Table 2 shows this comparison.

Table 2: Perception on the management of the competence of the students when initiating and finalizing the project.

\begin{tabular}{|l|c|c|c|c|c|c|}
\hline \multirow{2}{*}{ Level } & \multicolumn{2}{|c|}{ Communication } & \multicolumn{2}{c|}{ Collaborative work } & \multicolumn{2}{c|}{ Use of Technologies } \\
\cline { 2 - 7 } & Start & End & Start & End & Start & End \\
\hline Null & $0 \%$ & $0 \%$ & $0 \%$ & $0 \%$ & $0 \%$ & $0 \%$ \\
\hline $\begin{array}{l}\text { I could do } \\
\text { better }\end{array}$ & $11 \%$ & $7 \%$ & $8 \%$ & $20 \%$ & $4 \%$ & $0 \%$ \\
\hline I do it well & $\mathbf{5 1 \%}$ & $33 \%$ & $\mathbf{5 8 \%}$ & $7 \%$ & $47 \%$ & $20 \%$ \\
\hline $\begin{array}{l}\text { I do it } \\
\text { excellent }\end{array}$ & $38 \%$ & $\mathbf{6 0 \%}$ & $34 \%$ & $\mathbf{7 3 \%}$ & $\mathbf{4 9 \%}$ & $\mathbf{8 0 \%}$ \\
\hline
\end{tabular}


Regarding the results observed by the teachers, the following should be highlighted:

- VG students were able to understand the importance of documentation during the development of a multidisciplinary project. This project showed a change in the students' belief that documentation in software projects in education was simply to satisfy a class requirement, and that it did not have applications in the professional world.

- The students of DASWMD expressed feeling more motivated to make music for a video game that would be completely finished and that, in some cases, would be used by third parties. They also expressed their pleasure in being able to work in a context more similar to real life, collaborating actively with software developers to achieve a final product in common.

- It was observed that, in most cases, the students of DASWMD developed music libraries much more extensive and varied than those requested (at least) by their teacher to assign a grade in the project. They showed greater interest in providing quality elements for the benefit of the final product than in obtaining a grade for it.

- Students in general showed greater interest in performing in a better way since they reflected more commitment and felt part of a bigger project in which they were responsible for a greater job that would impact the peers of the other subjects.

With regard to the opinions expressed by the students, we can highlight the following:

- "The way we have more freedom in working hours, in learning; in the end the quality of the project depends on our own learning, instead of classes in which they teach us something and we are forced to use it. In that regard, I think it exceeded my expectations that we would be able to make a product that we really wanted to do. "

- "The way in which the creative aspect of the project is our own decision, without restrictions, since it was very interesting to be able to have different ideas without having to limit them because we have to limit the content to something that fit into the desired theme' ".

Figure 4 shows in a word cloud of the most frequently mentioned words by students when asked how they would define this activity. 


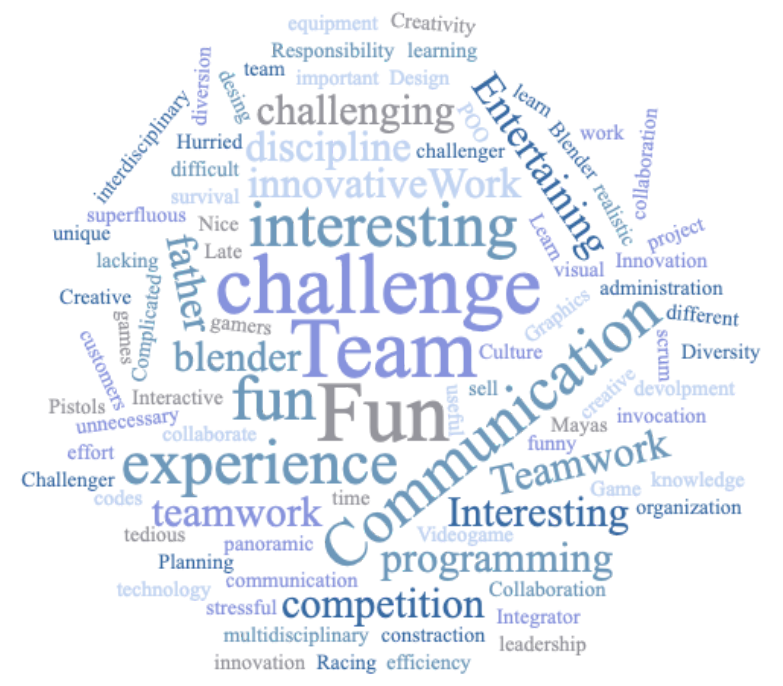

Figure 4: Cloud of words mentioned by students

\section{Future research}

As future research topics it is possible to consider a more strict design for the data collection instruments in order to develop a formal study that evaluates the impact of the proposed methodology in student's competencies. Other possible approach is the creation of a set of best practices for implementing the RAIS methodology in Universities, based on the experience acquired during the different semesters it is possible to create a primary draft that includes the basic information that needs to be considered for successful implementations.

\section{Conclusion}

By implementing a RAIS environment in this activity, students were able to contextualize their learning and felt a positive impact on the development of their communication skills, collaborative work and the use of technologies. Other findings derived from the comments and reactions of the students, indicate that they enjoy working on this type of projects, challenging them to improve their performance, which is reflected in the quality of their final products.

\section{Acknowledgment}

The authors appreciate the support received recently from a NOVUS grant from Tecnológico de Monterrey, Mexico to expand the scope of the project. The Centro de Escritura, campus Monterrey, for all the work done on the proofreading of this text. As well as the constant support of the Computing Department of the Monterrey campus in the development of this innovation. 


\section{References}

[1]Gutiérrez, D., Sandia, B., Hernández, D., Páez, G. and Lischinsky, P. lemph\{Integración de Conocimientos a Través del Desarrollo de un Producto RAIS. Caso de Estudio: Ingeniería de Software y Bases de Datos\}. EDUCERE. 19. 169, 2015.

[2]López, J. lemph\{Un giro copernicano en la enseñanza universitaria: formación por competencias. \} Revista de Educación, 356, 279-301, 2011

http://dx.doi.org/10-4438/1988-592X-RE-2010-356-040

[3]Medellín, M., Nieto, L., Zavala, H. y Díaz-Barriga, F. (1993). Implicaciones curriculares de la formación ambiental en la educación profesional. Revista Perspectivas Docentes, 11(73), 43-50.

[4]Rojas A. y Hawes, G. (2012). Articulación e integración en el currículum de formación profesional. REDU. Revista de Docencia Universitaria, 10(extra.), 55-81. 